\title{
THE USE OF COMBINED PRESERVATION TECHNIQUES FOR EXTENDED STORAGE OF
}

\section{ORTHOTOPIC LIVER HOMOGRAFTS}

\author{
LAWRENCE BRETTSCHNEIDER, M.D., Denver, Colorado, \\ PIERRE M. DALOZE, M.D., Montreal, Canada, CLAUDE HUGUET, M.D., Paris, France,
}

KENNETH A. PORTER, M.D., London, England,

CARL G. GROTH, M.D., Stockholm, Sweden, NOBORU KASHIWAGI, M.D., Chiba, Japan,

DAVID E. HUTCHISON, M.D., and THOMAS E. STARZL, M.D., F.A.C.S.,

Denver, Colorado

DURING THE 12 yeARs since homotransplantation of the whole canine liver was first described by Welch, there have been reports of several techniques of hepatic homograft preservation in dogs. Goodrich and his colleagues showed that livers removed at normal temperatures became unsuitable for transplantation within 20 or 30 minutes. The first protective device used in our laboratories (15) and by Moore and his associates was hypothermia, induced first by whole body cooling of the donor to 30 degrees $\mathrm{C}$. and then perfusing the excised liver with a chilled electrolyte solution. With a fall in the hepatic core temperature to approximately 15 degrees $\mathrm{C}$., these organs could support the life of recipient dogs if revascularized as orthotopic homografts within 2 hours. After longer times, there was a high rate of acute failure due to outflow block of the transplants, a hemorrhagic diathesis, and acute "liver failure. Almost identical conclusions about the efficacy of this simple approach were reached by Ono and

\footnotetext{
From the Department of Surgery, University of Colorado School of Medicine and the Denver Veterans Administration Hospital, Denver; and the Department of Pathology, St. Mary's Hospital and Medical School, London, England.

This work was supported by U. S. Public Health Service grants F05-TW-1154, AM 06283, AM 06344, HE 07735, AM 07772, AI 04152 , FR 00051 and FR 00069 , and by grants from the British Heart Foundation, Dr. Clark Memorial Fund, Medical Research Council, St. Mary's Hospital Research Fund, and the search Council, St.
Wellome Trust.
}

his co-workers in experiments which did not involve homotransplantation.

Subsequent efforts to extend the acceptable storage time have been disappointing. In dogs, Marchioro and his associates reported a method of hypothermic cadaveric perfusion with the use of an extracorporeal heart-lung apparatus into which a heat exchanger was incorporated. Either the entire corpse or the lower half of the dog was perfused. Orthotopic homotransplantation was performed with livers removed from 2 to 8 hours after the sacrifice of the donors. Eight of the 10 recipients which were treated with azathioprine survived operation, but all died within 1 to 5 days thereafter. Mikaeloff and Kestens and their associates used a similar principle in which hypothermic perfusion in situ was limited to the liver. They were able to obtain long term recipient survival after homotransplantation of canine livers removed as long as 6 hours after death. Their technique was an application of a method described several years earlier by Kestens and McDermott.

More complex methods have been tried. Brown and his colleagues have evaluated a combination of freezing to -6 degrees $\mathrm{C}$., immersion into a dimethylsulfoxide or glycerol bath, and dehydration. After 1 to 5 days, the organs were viable but severely dam- 


\section{Surgery, Gynecology \& Obstetrics - February 1968}

aged and apparently incapable of supporting life as orthotopic homografts. When Moss and his co-workers cooled livers to -20 to -60 degrees $\mathrm{C}$. for 1 to 14 days without dehydration, there was almost no function after the homografts were transplanted to the pelvis. Furthermore, all of the recipients died in 6 hours or less.

Recently, there have been 2 reports of conservation of hepatic homografts for 8 to 24 hours, a combination of perfusion, hypothermia, and hyperbaric oxygenation being used. Slapak and his associates placed puppy livers preserved in this way in the neck of adult recipients and found that bile was produced in 8 of 19 experiments. Their perfusing fluid did not contain red blood cells. In a preliminary report from our laboratory (3), chronic survival was described of adult canine recipients that received orthotopic hepatic homografts which had been preserved for almost a day after sacrifice of the donor. In these experiments, the perfusate contained diluted blood. As will be documented, further experience has shown that a significant rate of survival can be attained with such conserved organs if attention is paid to several important details.

\section{METHODS}

Organs were obtained from nonrelated mongrel donors and transplanted as orthotopic homografts by a modification of previously described techniques (Fig. 1). Anesthesia was with pentobarbital sodium, supplemented with phencyclidine hydrochloride. The recipients were 12 to 23 kilograms in weight.

Each of the donor dogs, which were of approximately matching size, was cooled to 30 to 34 degrees C. in an ice bath and sacrificed for removal of the liver. Just before and during donor hepatectomy, the liver was further cooled by an intraportal infusion with a balanced electrolyte solution, which had been buffered to $p_{\mathrm{H}} 7.45$ and chilled to 2 degrees $\mathrm{C}$. The constituents included 2.5 grams per hundred milliliters low molecular weight dextran, 150 milligrams per hundred milliliters glucose, 2 milliequivalents per liter magnesium sulfate, and 50 milligrams per liter procaine. A total of 1,000 to 2,000 milliliters was used.

Homografts for control experiments were transplanted as quickly as possible, revascularization in the recipient usually being completed within an hour. Organs which were to be preserved for longer periods had cannulas tied into the aorta and portal vein (Fig. 2, inset). The homografts were inserted into a hyperbaric chamber which was refrigerated at 4 degrees $\mathrm{C}$. Other aspects of the preservation technique which included perfusion and control of oxygen pressure were varied as will be defined in the different experimental groups.

During the subsequent transplantation, all dogs were given whole blood and 5 per cent glucose in lactated Ringer's solution. In each experiment, at least 500 milliliters of each were used, but more was given when needed. In addition, the recipients of preserved livers received 100 milligrams per kilogram epsilon aminocaprioc acid, 1 milligram per kilogram protamine sulfate, and 20 milliequivalents sodium bicarbonate at the time of homograft revascularization. Repeat doses of these drugs were very often necessary.

For all recipient dogs, immunosuppression was provided with intramuscularly administered antilymphocyte globulin and orally administered azathioprine and prednisone. The antilymphocyte globulin was usually started several days in advance of operation and continued daily for several weeks after. Azathioprine therapy was begun at the time of transplantation and given indefinitely in the maximum doses per day which did not cause leukopenia. A 1 week course of prednisone was administered in progressively diminishing daily doses which were started at 3 milligrams per kilogram on the day of operation.

Postoperative liver function was monitored with frequent measures of serum bilirubin, serum alkaline phosphatase, total protein, serum glutamic oxalacetic transami- 


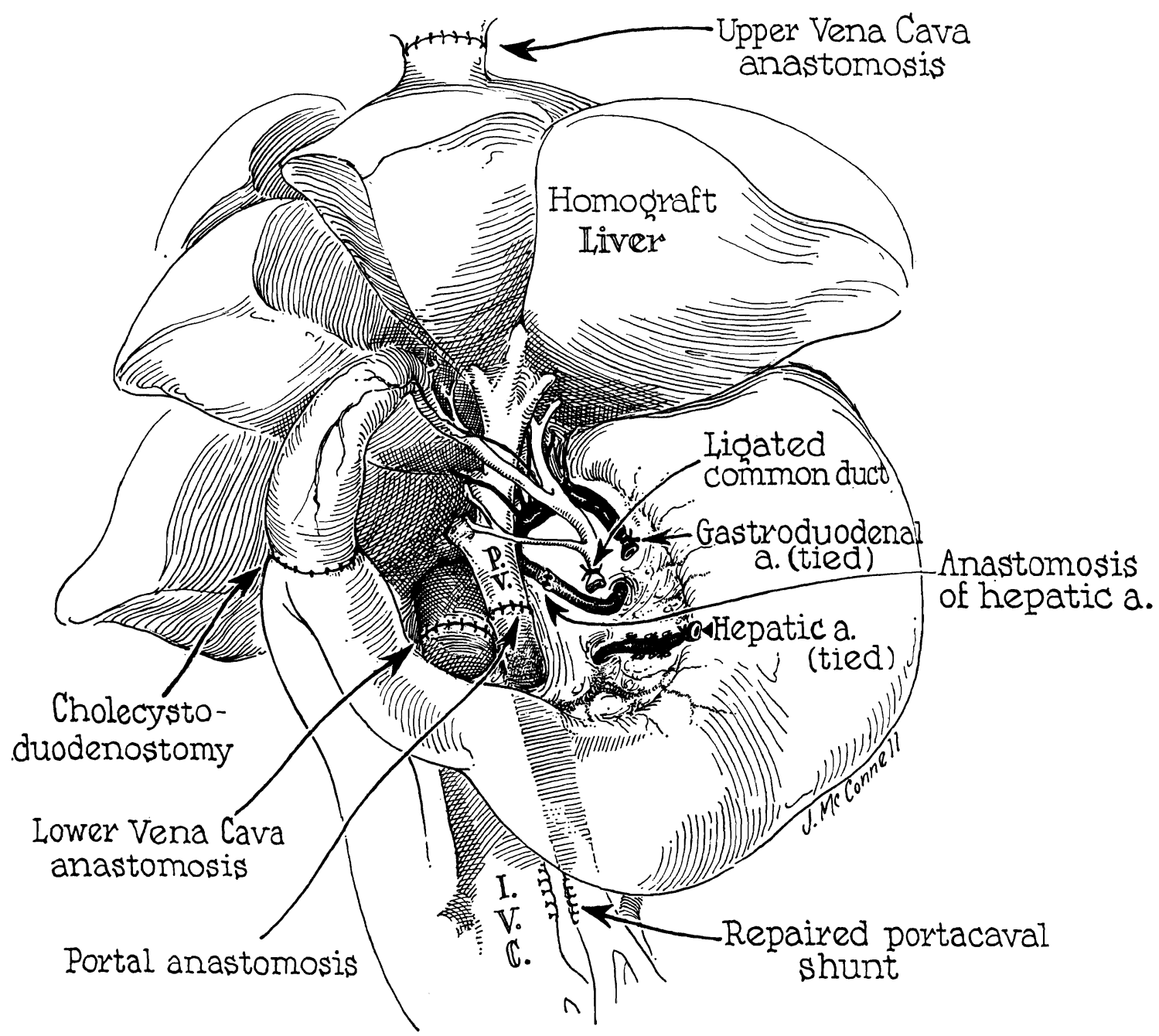

Fig. 1. Technique of orthotopic liver transplantation. The arterial supply is derived from the proximal part of the common hepatic artery by an end-to-end anastomosis to the proximal part of the recipient hepatic artery. The distal portion of the recipient artery and its inferiorly directed branches are left undisturbed. Failure to do so may result in duodenal necrosis.

nase, and serum glutamic pyruvic transaminase. In the event of death, autopsies were performed with particular attention being given to the state of the vascular anastomoses. Homograft tissue was fixed in 10 per cent formalin for eventual study with light microscopy.

Group 1, control. This group consisted of 12 dogs having homotransplantation without extended preservation.

Group 2, hyperbaric oxygenation and perfusion with diluted blood. Twenty-six homografts were placed in the hyperbaric chamber and continuously perfused with fresh homologous blood mixed with an equal volume of a solution identical to that employed for infusion, except that it contained 100 milligrams per liter heparin and 5 instead of 2.5 grams per hundred milliliters low molecular weight dextran. During preservation, the $p \mathrm{H}$ of the perfusate was frequently measured. If this fell below 7.2, it was corrected with sodium bicarbonate. A simple baffie runoff from the organ served as an oxygenator for the recirculated fluid (Fig. 2) which passed through a glass-wool filter and a bubble trap. Two oc- 


\section{Surgery, Gynecology \& Obstetrics · February 1968}

TABLE I.-RESULTS OF LIVER TESTS ON THE FIRST DAY AFTER TRANSPLANTATION GOMPARED TO THOSE IN 40 NORMAL DONORS

\begin{tabular}{|c|c|c|c|c|c|c|}
\hline Group & No. & Preservation time, hrs. & $\begin{array}{l}\text { Serum glutamic oxalace- } \\
\text { tic transaminase }\end{array}$ & $\begin{array}{c}\text { Serum glutamic pyruvic } \\
\text { transaminase }\end{array}$ & Alkaline phosphatase & Bilirubin \\
\hline Donors & 40 & - & $26 \pm 48$ & $29 \pm 74$ & $2.6 \pm 1.9$ & $0.2 \pm 0.2$ \\
\hline 1 & 15 & $1 / 2-11 / 2$ & $191 \pm 162$ & $524 \pm 367$ & $15.9 \pm 8.8$ & $0.7 \pm 1.1$ \\
\hline $2 \mathrm{~A}$ & 7 & $10-14 \frac{1}{2}$ & $634 \pm 432$ & $975 \pm 444$ & $19.2 \pm 12.8$ & $0.5 \pm 0.3$ \\
\hline $2 B$ & 5 & $8-91 / 2$ & $353 \pm 220$ & $174 \pm 141$ & $12.8 \pm 3.6$ & $1.2 \pm 1.7$ \\
\hline $2 B$ & 5 & $111 / 2-151 / 2$ & $940 \pm 981$ & $1788 \pm 1330$ & $12.4 \pm$ & $0.8 \pm 0.6$ \\
\hline $2 \mathrm{C}$ & 5 & $8-91 / 2$ & $291 \pm 208$ & $568 \pm 754$ & $8.8 \pm 2.6$ & $0.7 \pm 0.4$ \\
\hline $2 \mathrm{C}$ & 3 & $243 / 4-251 / 6$ & $367 \pm 29$ & $472 \pm 158$ & $6.1 \pm 2.5$ & $0.5 \pm 0.3$ \\
\hline
\end{tabular}

Mean values and standard deviation given.

clusive roller pumps were used outside of the chamber. The oxygen compression of 40 pounds per square inch gauge pressure was reached within 20 minutes after inserting the organs. Various subgroups of experiments differed in the following important details:

A, low flow, rapid decompression.--Seven of the homografts were preserved for 10 to $141 / 2$ hours. The portal venous and hepatic arterial flows were low, approximately 2.4 milliliters and .6 milliliter per gram per hour, respectively. Before removal of the homografts from the chamber, hyperbaric decompression was carried out for an interval of 25 to 35 minutes.

B, low flow, slow decompression.-The perfusion rate was the same as that used in A but the decompression time for the chamber was slower, having been extended to 3 to 4 hours. Five homografts were stored for 8 to $91 / 2$ hours, and 5 more for a period of $111 / 2$ to $151 / 2$ hours.

$\mathrm{C}$, higher flow, slow decompression.-The flow rate to the 2 inflowing vessels was doubled, approximately to 4.8 and 1.2 milliliters per gram liver per hour for the portal vein and hepatic artery, respectively. Five homografts were transplanted after preservation for 8 to $91 / 2$ hours. Five more were preserved for $243 / 4$ to $251 / 6$ hours.

Group 3, oxygenation at atmospheric pressure and perfusion with diluted blood. Three homografts were preserved for $201 / 4$ to $251 / 4$ hours under the same conditions as in group $2 \mathrm{C}$, except that 100 per cent oxygen was used at atmospheric pressure.

Group 4, hyperbaric oxygenation and perfusion with noncellular fluid. The conditions were the same as in group $2 \mathrm{C}$, except that blood was not added to the perfusate. Storage for the 5 homografts ranged from $21 \frac{1}{4}$ to $241 / 2$ hours.

Group 5, hyperbaric oxygenation. Three homografts were preserved for $221 / 2$ to 25 hours under the same conditions as in groups $2 \mathrm{~B}$ and $2 \mathrm{G}$, except that continuous perfusion was not provided. In 2 instances, the cooled grafts were immersed in a basin of noncellular perfusion fluid within the refrigerated chamber. In the other, perfusion was carried out with the same solution for 30 minutes at 6 milliliters per gram tissue per hour to ensure core cooling. The pumps were then turned off. The organ was not immersed in fluid.

\section{RESULTS}

Group 1. Two of the control dogs died of hepatic artery occlusion after 4 and 7 days, and 2 died of rejection in 7 and 8 days. The 8 remaining controls lived for 3 weeks or more, 6 surviving for at least 6 weeks. Using a maximum credit of 70 days for any individual dog, the mean survival time for the group was $38.7 \pm 29.8$ days, S.D. These results indicated that the immunosuppression being used was effective.

There was evidence of moderate ischemic injury as judged by liver function tests obtained in the recipient 18 to 24 hours postoperatively (Table I), but these changes were highly reversible. There were no unusual problems with operative hemorrhage. On the day of transplantation, the dogs received 400 to 500 milliliters of blood as well as 500 to 1,000 milliliters electrolyte solution. 


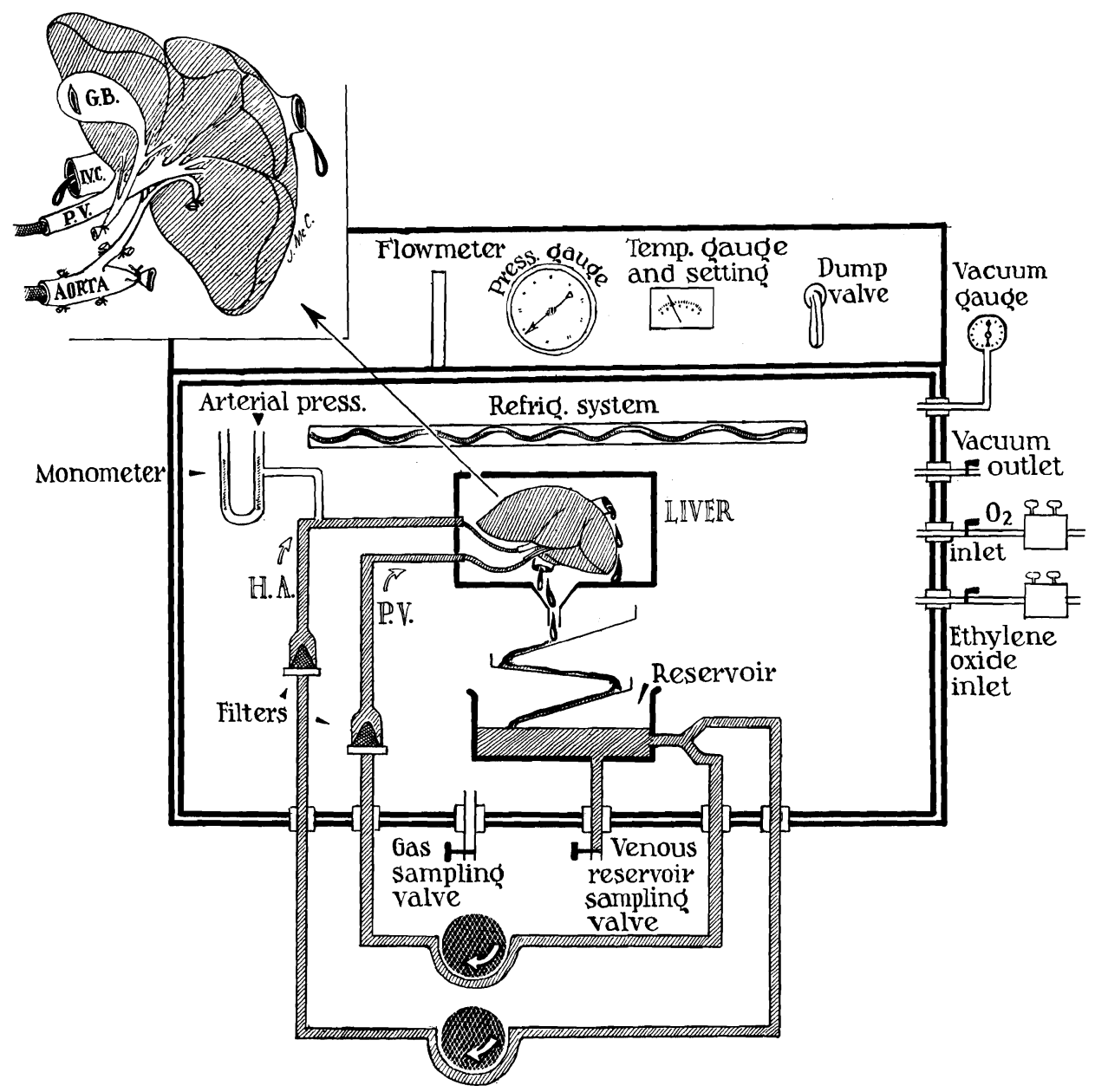

Fic. 2. Preservation unit. The perfusion pumps are located outside of the hyperbaric chamber. The organ receptacle, the oxygenator, and the venous reservoir are inside. The various chamber inlets permit sampling of the perfusate, gas sterilization, and oxygen delivery and removal. The temperature is electronically controlled.

At autopsy, the liver homografts were similar to those from previously reported series (16). In the hepatic homografts from the 4 dogs that died at 7 to 21 days after rejection, there was dense infiltration by large lymphoid cells and plasma cells around the portal and central veins. There was also necrosis of the majority of the hepatocytes in the central and middle zones of the liver lobule together with collapse and condensation of the reticulin framework of the central parts of the lobules. The hepatic homografts from 2 of those that survived longer were normal. In the other 2 grafts, there were bands of condensed reticulin linking adjacent central veins, slight lymphoid cell infiltration in the central and portal areas, and plugs of bile pigment in the centrilobular bile canaliculi.

Group 2. In the subgroup A, large numbers of gas bubbles appeared in the perfusion lines during rapid decompression. Most of the homografts had a spongy consistency due to similar gas emboli within the parenchyma, an observation which was confirmed roentgenographically. The organs generally gained weight, the average increase during residence in the chamber being 16.6 per cent. 


\section{$6 \quad$ Surgery, Gynecology \& Obstetrics · February 1968}

After revascularization, the livers did not develop outflow block or regional infarcts, and after 30 to 60 minutes, they appeared to be perfused relatively homogeneously. At, or just before, this time, a hemorrhagic diathesis was evident to some degree in every dog despite prior therapy with epsilon aminocaproic acid and protamine sulfate. On the day of operation, at least 1,000 milliliters of blood and 2,000 to 3,000 milliliters of electrolyte solution were required. When insufficient quantities of the latter fluids were not provided, there was a drastic hemoconcentration with hematocrits as high as 76 per cent.

Six of the 7 dogs survived operation; the seventh died within a few hours for reasons not apparent at autopsy. The remaining dogs lived for 2, 3, 5, 5, 7, and 9 days, but their courses were not satisfactory. They were slow to recover from anesthesia, in some instances requiring several days to awaken fully. Two had generalized convulsions within minutes after homograft revascularization, a complication which was suspected to be caused by air emboli originating from the grafts. None were ever able to eat. In several dogs ascites and anasarca rapidly developed. Four of the 6 dogs which survived operation eventually had perforations of the duodenum, esophagus, or gallbladder.

On the day after homotransplantation, there was biochemical evidence of severe ischemic injury (Table I) which could be detected in the results of all the enzyme determinations. Subsequently, these values tended to return toward normal. An elevation in bilirubin to more than 1 milligram per hundred milliliters was seen in only $1 \mathrm{dog}$ during the first 3 postoperative days. However, there was severe and persistent depression of serum proteins to as low as 3.5 grams per hundred milliliters.

Histologic examination of the homografts showed evidence of rejection in those dogs that survived for 5 days or more, but there were no other unusual lesions. There was ischemic necrosis of the centrilobular hepatocytes in the homograft from the dog that died 3 days after transplantation. Another homograft, examined 2 days after grafting, appeared normal.

In subgroup $B$, those with low flow and slow decompression, the gross evidence of gas emboli was greatly reduced. The weight of the organs was stable during preservation, the average change being -0.6 per cent. Serious outflow block after transplantation was not observed.

The difficulties of supportive care for these dogs was less than for those of group 2A, as reflected by a somewhat reduced requirement for blood and electrolyte solution on the day of operation. Arousal from anesthesia was more prompt.

Four of the 5 recipients of homografts which had been preserved for 8 to $91 / 2$ hours survived operation, but 3 of these died after 4,11 , and 14 days. One dog is still alive after more than 4 months. With preservation for $11 \frac{1}{2}$ to $15 \frac{1}{2}$ hours, the results were similar. All 5 dogs lived through the operation, but 4 died later after 5, 6, 6, and 13 days. The other is still in good health after $51 / 2$ months (Fig. 3).

The reason for the paucity of chronic survivors in this group was not initially clear. There was biochemical evidence of acute ischemic injury, particularly in the organs which had been preserved for $111 / 2$ to $151 / 2$ hours (Table I). However, the postoperative changes after storage of 8 to $91 / 2$ hours were not significantly different than in the controls of group 1 (Table I) and these returned toward normal with approximately equal rapidity. The rapid resolution of the enzyme changes did not imply a comparably fast restoration of total liver function. There was a severe depression of total serum proteins which had not returned to normal by the fifth postoperative day (Fig. 4).

Only 2 of the 8 homografts from experiments in which the recipients died in 2 weeks or less showed evidence of acute rejection. Evidence of healing ischemic centrilobular hepatocyte injury was present in the other 6 livers in this group. This was accompanied in 2 instances by centrilobular cholestasis. The 


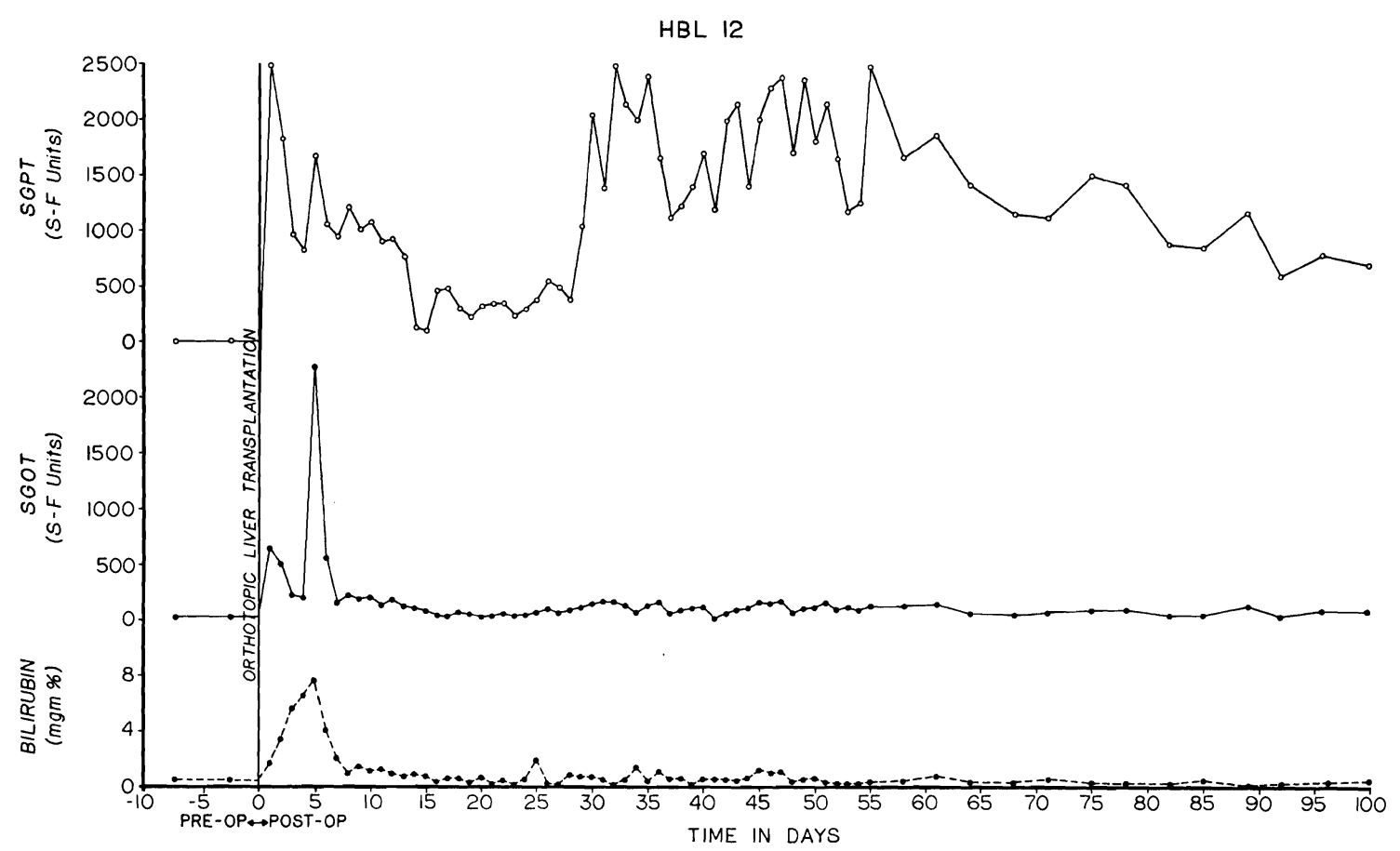

FIG. 3. The first 100 postoperative days of a dog which received an orthotopic liver homograft after preservation for $141 / 2$ hours. The total liver perfusion was only 3 milliliters per gram tissue per hour, a rate thought to be inadequate. Note the early evidence of reversible ischemic injury. The later rise in serum glutamic pyruvic transaminase was probably due to low grade rejection. The dog is still alive after $51 / 2$ months. This dog, as well as all others in the study, was treated with azathioprine, a short postoperative course of prednisone, and antilymphocyte globulin.

degree of ischemic injury was not detectably different when preservation was for 8 to $91 / 2$ hours as compared to $111 / 2$ to $151 / 2$ hours.

In group $2 \mathrm{C}$, those with higher flow and slow decompression, the homografts preserved for 8 to $91 / 2$ hours lost an average of 4.2 per cent of their weight during residence in the chamber, and seemed grossly to be in excellent condition. After subsequent revascularization, none developed outflow block. The 5 dogs which received these livers survived operation. They required an average of 700 milliliters of blood and 1,500 milliliters of electrolyte solution on the day of transplantation. Arousal from anesthesia was prompt.

Two dogs died after 9 and 19 days from rejection and multiple liver abscesses, respectively. The other 3 lived for 34, 46, and 97 days. With a maximum credit for individual dogs of 70 days, the mean survival was 35.6 \pm 23.9 days S.D.
The degree of ischemic injury which was detectable with liver function studies on the first postoperative morning was comparable to that in the control experiments (Table I). Moreover, the depression in serum protein was not so great as in dogs of groups $2 \mathrm{~A}$ or $2 \mathrm{~B}$, and it had returned to normal within 5 days (Fig. 4).

The homografts preserved for more than 24 hours under the same conditions were less satisfactory. During storage, they gained an average of 4.3 per cent weight. After transplantation, they appeared to be well perfused, but an uncontrollable hemorrhagic diathesis developed in 2 of the recipients. In the other 3 , liver function tests on the next morning were more abnormal than had been the case with the shorter interval. Nevertheless, only 1 of these 3 dogs died early, after 8 days; another died after 46 days. The third dog is still alive after 4 months (Fig. 5).

Pathologic studies of the livers preserved 


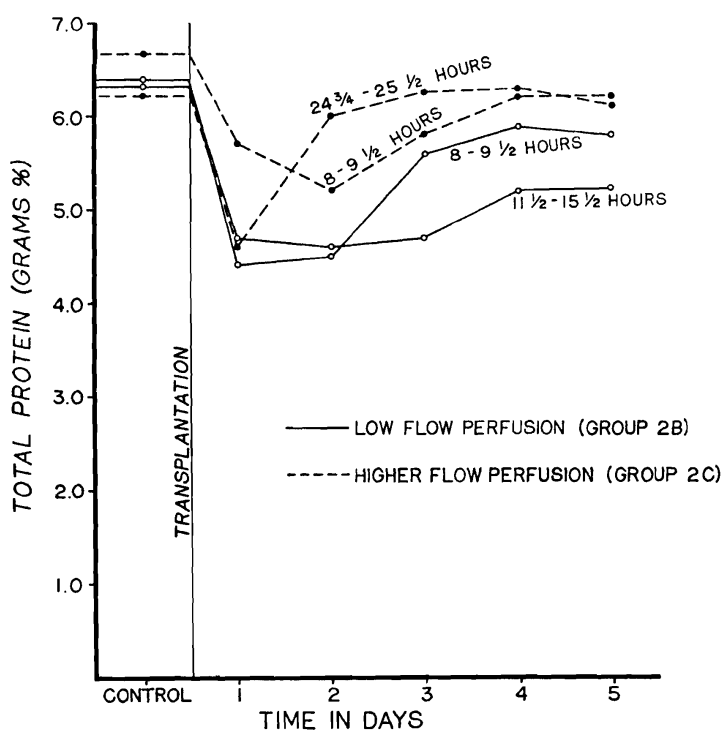

Fig. 4. The effect of both preservation time and perfusion rate upon circulating plasma proteins. There is profound and sustained hypoproteinemia in the dogs which received grafts that had been preserved with low flow perfusion as compared with the results using a higher flow rate.

for the shorter time showed that 2 were undergoing rejection after 9 and 34 days. In both, dense infiltrations of lymphoid cells were present around the central and portal veins and there was marked necrosis of the central and midzonal hepatocytes. Two other hepatic homografts, from dogs which survived 19 and 46 days, respectively, showed some residual centrilobular scarring with atrophy of the hepatocytes immediately adjacent to central veins and increased numbers of reticulin fibers around the vein walls. Centrilobular cholestasis was also a feature of both livers. The 2 livers which were preserved for more than 1 day and recovered within a few hours after revascularization showed necrosis of the centrizonal hepatocytes but no other injury. The other, which was studied 8 days later, showed extensive necrosis, only those hepatocytes adjacent to the portal tracts surviving. There was no evidence of rejection.

Group 3. The oxygen pressure of the perfusate was maintained at 250 millimeters of mercury or more. The weight gain of the 3 homografts averaged 27.1 per cent during preservation. The livers had a patchy discoloration. All 3 gallbladders had grossly necrotic foci in the mucosa, and in 2 of these extensive intramural hematomas developed during the extracorporeal perfusion. After transplantation, severe outflow block was immediately evident with consequent extreme portal hypertension. The 3 recipients of these badly injured organs all died within 6 to 28 hours of acute hepatic failure and intra-abdominal hemorrhage.

Histologic examination of the 3 livers showed widespread necrosis of hepatocytes, only a few surviving immediately beneath the capsule.

Group 4. The homografts which lost an average of 1.9 per cent weight appeared grossly to be well preserved. There were no mucosal defects in the gallbladder. After transplantation, none of the livers developed outflow block. Nevertheless, 4 recipients of these organs died of acute liver failure and intra-abdominal hemorrhage within a few hours after operation. The fifth, which received a homograft that had been stored for $211 / 4$ hours, had a serum glutamic pyruvic transaminase of 1,600 on the first postoperative day but lived for 9 more days with poor liver function throughout this particular period.

Only 1 of the homografts from the dogs which died early showed extensive necrosis of hepatocytes. In the other 3 livers, the hepatocytes in the central zones of the lobules were dead, but the others looked viable. There were no other changes. The homograft studied after 10 days showed evidence of rejection. The portal and central areas of the lobules were densely infiltrated by mononuclear cells, many of which possessed pyroninophilic cytoplasm. There was also hemorrhagic necrosis of the central and midzonal hepatocytes.

Group 5. The average weight loss of the homograft was 4 per cent. Slough of the gallbladder mucosa was severe in 1 of the homografts and minor in the others. Otherwise, the livers seemed to be in good condition. 


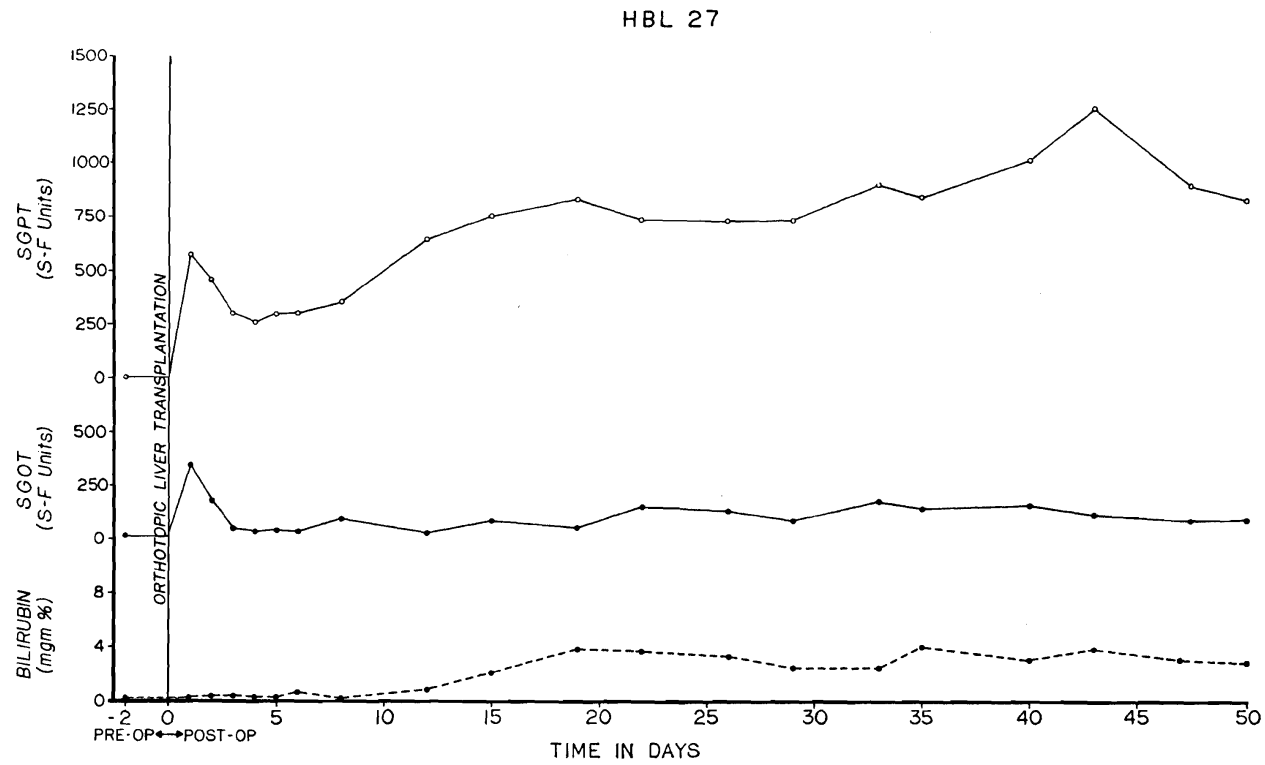

Fig. 5. The course of a dog which received an orthotopic liver homograft which had been preserved for $243 / 4$ hours. The perfusion rate was twice that used for the experiment shown in Figure 3. There is relatively minor biochemical evidence of early ischemic injury. The dog is still alive after 4 months.

After transplantation, 2 of the recipients died within 12 to 18 hours of acute liver failure. The other dog, which had a serum glutamic pyruvic transaminase of 2,000 on the first postoperative day, never fully awakened from anesthesia and died after $31 / 2$ days.

The homografts from dogs which died within 18 hours showed widespread necrosis of liver cells affecting all parts of the lobules. After $31 / 2$ days, the other organ showed centrilobular hepatocyte cholestasis. There were also bile casts in the larger bile ducts.

\section{DISCUSSION}

A quantitative biochemical analysis of the response of canine liver tissue to ischemia has been published by Sicular and Moore. The ability of liver slices to oxidize glucose normally was retained for 30 to 60 minutes after death under normothermic conditions and for several hours if the tissue was refrigerated. These and other studies, such as those by Van Wyk and his associates, provided ample proof that the injury which follows cessation of hepatic circulation is a graded one which can be considerably slowed by the im- portant emergency measure of immediately cooling the organ.

Unfortunately, the provision of metabolically active hepatic tissue does not necessarily mean that the organ can sustain life, particularly when the recipient animal is made totally dependent upon the homograft as is evident with orthotopic homotransplantation. This is well illustrated by the results reported herein. In some experiments, the quality of immediate liver function was sufficient to allow prompt recovery from anesthesia with subsequent long term survival. At the other end of the spectrum were dogs which died of liver failure within just a few hours.

Between these extremes were many examples of dogs with more or less grave acute hepatic insufficiency. The operative and postoperative care of these dogs was difficult. A severe bleeding diathesis was invariable, which usually required multiple blood transfusions, extraordinary mechanical efforts at hemostasis, and the administration of clot-promoting agents, such as epsilon aminocaproic acid and protamine sulfate. 
The clotting defect, which has been shown by von Kaulla and his associates to be partly due to increased levels of circulatory fibrinolysins, is a complex one which is currently under study.

In such instances, control of bleeding was only the first step. Intensive therapy was required with electrolyte solutions or plasma, apparently because of the rapid formation of a third fluid space particularly within the abdomen but also in peripheral tissues. Detoxification of the barbiturate anesthesia was slow. The rapid fall of serum protein levels was an ominous sign. There was a high incidence of acute gastrointestinal ulcerations. With intensive care, these dogs could often be kept alive for several days, but they would not eat. Almost all died in less than 10 days. Although the homografts which were examined at autopsy often had evidence of early rejection in spite of immunosuppressive therapy, the predominant histologic changes were those of healing ischemic damage.

In this study, a number of modifications of preservation technique were tried, the condition of hypothermia being identical in each instance. The most successful method was with an adaptation of the system described for kidneys by Ackermann and Barnard, using a combination of hypothermia, hyperbaric oxygenation, and divided perfusion with diluted blood through the portal vein and hepatic artery at a total flow rate of 6 milliliters per gram of liver per hour. Both immediately and later, homografts which were stored under these conditions for 8 hours performed approximately as well as livers transplanted without delay. When attempts were made to extend the preservation time to 24 hours, only 3 of 5 recipients survived operation, although 2 of these lived for at least $61 / 2$ postoperative weeks.

Systematic variations from the protocol already mentioned were evaluated to determine which details of technique were important and which were nonessential. Every deviation tried led to a deterioration of the results. Thus, a reduction in the rate of perfusion by half resulted in a demonstrably greater ischemic injury during storage for 8 hours. By using preservation for 24 hours as the test system, life-sustaining homografts could not be obtained if either hyperbaric oxygenation or perfusion, or even the blood fraction of the perfusate, were eliminated.

Beneficial effects of cold and perfusion for the preservation of organs are neither surprising nor difficult to explain. The reason for the apparently important role played by hyperbaric oxygenation is less clear. It is conceivable that the principal value of hyperbaria in these studies was that it increased the efficiency of the simple oxygenator which was kept within the compression chamber. Less likely is the possibility that oxygen diffusion through the surface of the organs was a significant factor, since this is thought to occur only to a depth of a few millimeters.

Manax and his associates have suggested other intriguing hypotheses. They have drawn attention to the metabolic inhibition which accompanies high atmospheric pressure, a desirable effect which has been demonstrated by Lyons and his colleagues to occur with nitrogen as well as with oxygen. Finally, mechanical influences, such as compression of the vascular system, may be helpful by preventing the formation of edema. It is of interest in our experiments that substantial weight gain of the preserved organs occurred only when hyperbaric oxygenation was omitted and that it was only in these homografts that outflow block was consistently observed.

The demonstration that livers can be kept in good condition for at least 8 and often for 24 hours after the death of the donor may have important clinical implications. It should be possible with this amount of time to prepare a patient to receive a homograft without the sense of urgency which has characterized past efforts at human liver transplantation. Preliminary analysis of donor and recipient histocompatibility antigens could be carried out in the interval.

However, other factors may diminish these hopes. In the laboratory, the timing of donor and recipient procedures can be precisely 
co-ordinated. The homograft which is taken from a cooled donor has a blood supply until virtually the moment of its excision. These ideal conditions are not attainable with cadaveric donors, since failing organ perfusion has invariably been present for sometime before death and because the liver must usually be in a normothermic postmortem state for some minutes before cooling can be instituted. At present, the extent to which the acceptable margin of ischemia has been dissipated before protective measures can be started appears to pose a more serious problem than that of efficient subsequent preservation.

\section{SUMMARY}

Orthotopic liver transplantation was performed with homografts that had been preserved for 8 to 25 hours after their removal from nonrelated mongrel donors. The fate of the recipients was compared to that of control dogs which received homografts transferred as rapidly as possible from cooled living donors. All dogs were treated postoperatively with immunosuppressive agents.

Homografts could be effectively preserved for 8 hours and often for as long as 24 hours with a combination of hypothermia at 4 degrees C., hyperbaric oxygenation 'at $31 / 2$ to 4 atmospheres, and divided perfusion with diluted homologous blood through the portal vein and hepatic artery at a total rate of 6 milliliters per gram tissue per hour. At the end of the conservation period, the chamber was decompressed during 3 to 4 hours. The short term and long term course of 5 recipients of livers preserved for 8 hours was not different from that of control dogs. All dogs survived operation, and only 1 dog died in less than 19 days. Three of 5 recipients of livers preserved for 24 hours survived operation and 1 of these is still alive after a period of 4 months.

Deviations from this technique were evaluated with additional groups of 3 to 5 experiments in which livers were stored for 24 hours. Omission of perfusion or reduction of its rate by half, elimination of hyperbaric oxygenation, rapid chamber decompression, or failure to add homologous blood to the perfusate all resulted in less satisfactory results. The recipients of these homografts either died during operation or within a few hours or days thereafter. They usually had grave clotting abnormalities, evidence from serum enzyme measurements of severe hepatocellular injury, retardation of protein synthesis, and a high incidence of gastrointestinal ulceration. The impression that these livers had suffered from ischemic necrosis was confirmed by histologic studies.

\section{REFERENCES}

1. Ackermann, J. R. W., and Barnard, C. N. A report on the successful storage of kidneys. Brit. J. Surg., 1966, 53: 525 .

2. Brown, H., Patel, J., Blair, D. W., and Brown, M. E. Biochemical studies with preserved transplanted canine liver. J. Am. M. Ass., 1966, 196: 775.

3. Brettschneider, L., Daloze, P. M., Huguet, C., Groth, C. G., Kashiwagi, N., Hutchison, D. E., and StarzL, T. E. Successful orthotopic transplantation of liver homografts after 8-25 hours preservation. Surgical Forum; Clinical Congress 1967. Vol. XVIII. Chicago: American College of Surgeons, 1967 , p. 376.

4. Goodrich, E. D., Welsh, H. F., Nelson, J. A., BeEcher, T. S., and Welch, C. S. A report on homotransplantation of the canine liver. Surgery, 1956, 39: 244.

5. Kestens, P. J., and McDermott, W. V., JR. Perfusion and replacement of the canine liver. Surgery, 1961, 50: 196.

6. Lyons, G. W., Dietzman, R. H., and Lillehei, R. C. On the mechanism of preservation with hypothermia and hyperbaric oxygen. Tr. Am. Soc. Artif. Int. Organs, 1966, XII: 236.

7. Manax, W. G., Bloch, J. H., Longerbeam, J. K., and Lillehei, R. C. Successful 24 hour in vitro preservation of canine kidneys by the combined use of hyperbaric oxygenation and hypothermia. Surgery, 1964, 56: 275

8. Marahioro, T. L., Huntley, R. T., Waddell, W. R., and Starzl, T. E. The use of extracorporeal perfusion for obtaining post mortem grafts. Surgery, 1963, 54: 900.

9. Mikaeloff, P., Kestens, P.J., Dureau, G., Rassat, J. P., Haxhe, J, J., Alexandre, G., Dubernard, J. M., Cuilleret, J., Hassoun, A., Maldague, P., Morelle, J., and Descotes, J. Transplantation orthotopique du foie chez le chien apres conservation de l'organe par perfusion. Mem. Acad. chir. Par., 1965, 91: 711.

10. Moore, F. D., Wheele, H. B., Demissianos, H. V., Smith, L. L., Balantura, O., Abel, K., GreenBERG, J. B., and DAMmin, G. J. Experimental wholeorgan transplantation of the liver and of the spleen. Ann. Surg., 1960, 152: 374.

11. Moss, G. S., Reed, P., and Riddell, A. G. Observations on the effects of glycerol on the cold storage of the canine liver. J. Surg. Res., 1966, 6: 147.

12. Ono, H., Buckberg, G. D., and Longmire, W. P., $\mathrm{JR}$. Asanguineous hypothermic liver perfusion in the dog. J. Surg. Res., 1967, 7: 152. 
12 Surgery, Gynecology \& Obstetrics - February 1968

13. Sicular, A., and Moore, F. D. A study of the post mortem survival of tissues. J. Surg. Res., 1961, 1: 16 .

14. Slapak, M., Wigmore, R. A., and McLean, L. D. Twenty-four hour liver preservation by the use of continuous pulsatile perfusion and hyperbaric oxygen. Transplantation, 1967, 5: 1154

15. Starzl, T. E., Kaupp, H. A., Brock, D. R., LazARUS, R. E., and Johnson, R. U. Reconstructive problems in canine liver homotransplantation with special reference to the postoperative role of hepatic venous flow. Surg. Gyn. Obst., 1961, 112: 135.

16. Starzl, T. E., Marchoro, T. L., Porter, K. A., TAYlor, P. D., Faris, T. D., HermanN, T. J.,
HLad, C. J., and Waddell, W. R. Factors determining short and long term survival after orthotopic liver homotransplantation in the dog. Surgery, 1965, 58: 131 .

17. VAN WYK, J., TAIt, I. B., and EIseman, B. Function of the liver left for graded periods within the cadaver. Surgery, 1965, 58: 374.

18. von Kaulla, K. N., Kaye, H., von Kaulla, E., Marchioro, T. L., and Starzl, T. E. Changes in blood coagulation before and after hepatectomy or transplantation in dogs and man. Arch. Surg., 1966, 92: 71.

19. WELCH, C. S. A note on the transplantation of the whole liver in dogs. Transpl. Bull., 1955, 2: 54. 